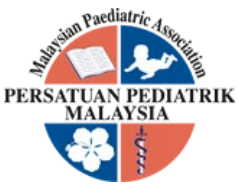

\title{
OBSERVE YOUR CHILD ABLUTION; THEY COULD HAVE OBSESSIVE- COMPULSIVE DISORDERS
}

\author{
Norzila Zakaria', Ahmad Shahril Ab. Halim', Ramiza Ramza Ramli², Raishan Shafini Bakar', \\ Agustine Nengsih Fauzi ${ }^{3}$, Nur-Fazimah Sahran ${ }^{4}$, Mohd Noor Mamat ${ }^{5}$
}

Received: 25 December 2019 ; Accepted revised manuscript: 31 March 2020

Published online: 06 April 2020

\section{Introduction}

Obsessive-compulsive disorder (OCD) is a neuropsychiatric disorder characterized by recurrent intrusive, distressing thoughts and repetitive behaviours or mental rituals performed to reduce anxiety. The lifetime prevalence of OCD is $2.3 \%$ and it can happen to all people of various levels, including child and adolescent. The mean age of onset is 19.5 years, and a subset of patients, mostly males, have an early onset before 10 years of age. The lifetime risk of developing OCD is higher in females, who typically develop the disorder in adolescence [1]. Person with OCD usually presented with obsession involving various themes, namely contamination; repeated doubts; religious, need for symmetry and exactness, or taboo thoughts of a sexual, religious, or aggressive nature. Whereas, the most common compulsions are checking, washing, hoarding, and counting compulsions [1].

Children with early-onset OCD are often underdiagnosed for multiple reasons such as children hide the symptoms from their parents, and the parents are not aware of the symptoms $[2,3]$. These symptoms can affect their daily activities, including performing worship. The aim of this article is to highlight the possibility of excessive practice in performing wudhu/ablution among children as the initial sign of OCD among them.

\section{Discussion}

Wudhu is a ritual purification prescribed as washing parts of the body. It is done following commandments which making sure that the body parts are washed following a determined order: washing the face, washing the forearms, wiping the head, and washing the feet. The ablution is usually done as to pure oneself to do preceding rituals, e.g. the daily prayers. Just like most of the Islamic rituals, Muslims try their best to follow what Prophet Muhammad (PBUH) practised and this is called to follow the Sunnah. In ablution, besides the compulsory order of the washing, there are several sunnah that we carry out, for example, washing thoroughly each body part three times.

Muslim children are taught about ablution (wudhu) before they perform the five times prayers (salat) by their parents at home. At school, these are taught during Islamic Education classes, and the practices are observed by the teachers (Ustaz) to ensure it is done to near perfect to the Islamic guidelines.

\footnotetext{
'Department of Psychiatry, School of Medical Sciences, Universiti Sains Malaysia, 16150, Kubang Kerian, Kelantan. 2 Department of Otorhinolaryngology Head and Neck Surgery, School of Medical Sciences, Universiti Sains Malaysia, 16150, Kubang Kerian, Kelantan

${ }^{3}$ Department of Chemical Pathology, School of Medical Sciences, Universiti Sains Malaysia, 16150, Kubang Kerian, Kelantan

${ }^{4}$ Nutrition \& Dietetics Programme, School of Health Sciences, Universiti Sains Malaysia, 16150, Kubang Kerian, Kelantan

${ }^{5}$ Environmental \& Occupational Health Programme, School of Health Sciences, Universiti Sains Malaysia, 16150, Kubang Kerian, Kelantan

Corresponding author: Dr. Ahmad Shahril Ab. Halim, Department of Psychiatry, School of Medical Sciences, Universiti Sains Malaysia, 16150, Kubang Kerian, Kelantan. Telephone: 609767 6715; Email: shahrilabhalim@usm.my
} 
OCD is diagnosed when the obsessions and/or compulsions cause marked distress, are recognized at least at some point as being excessive and/or irrational, are time consuming, and significantly interfere with the person's functioning [4]. In the case of an OCD Muslim school-age child, one can observe the obsessiveness and compulsion in their practice of wudhu. For them, the completeness of each washing in wudhu, which are the face, arms, head and feet, have to be repeatedly washed to ensure it abides the sunnah and at the same time to be performed correctly so that their prayer will be accepted. Therefore, typically they would spend long hours in the bathroom doing ablution and as a result, delaying their other activities such as being late to school. Being over meticulous in doing their ablution, some of them even wet their school uniforms while preparing for their afternoon prayers (Zuhr) which they usually performed at school. Sometimes, it involves them repeating whole ablution process after had thoughts of inadequacy during the prior attempt. This religious OCD symptom is known as scrupulosity and typically involves the perception of making sin where there is none and focused on minor details of one's religious practice [5].
It is a challenge for psychiatrists to treat children through a religious approach [5] due to differences in cognitive development. Therapists need to have good knowledge and understanding about the steps and rationale of performing wudhu and salat, e.g. the compulsory and the sunnah part for each practice, and how to adjust these practices therapeutically. For example, how to make the children understand they need to do all washings in wudhu once (compulsory) rather than three times (sunnah). It is important to be able to discuss what are the rationales of choosing between the two procedures so that they do not feel guilty if they do not follow the sunnah of the Prophet Muhammad (PBUH). Perhaps, more emphasize should be taken into how the Prophet take the easier steps between two choices and avoid wasting of water in ablution process to instil better understanding regarding the issue. Likewise, other behaviour therapy such as breathing exercise, thought-stopping and response prevention should be emphasised because these could be helpful in making them calmer and avoiding them from reinforce the compulsive behaviour. Figure 1 is an algorithm for the approach to treat ablution ritual related

Obsession of ablution ritual
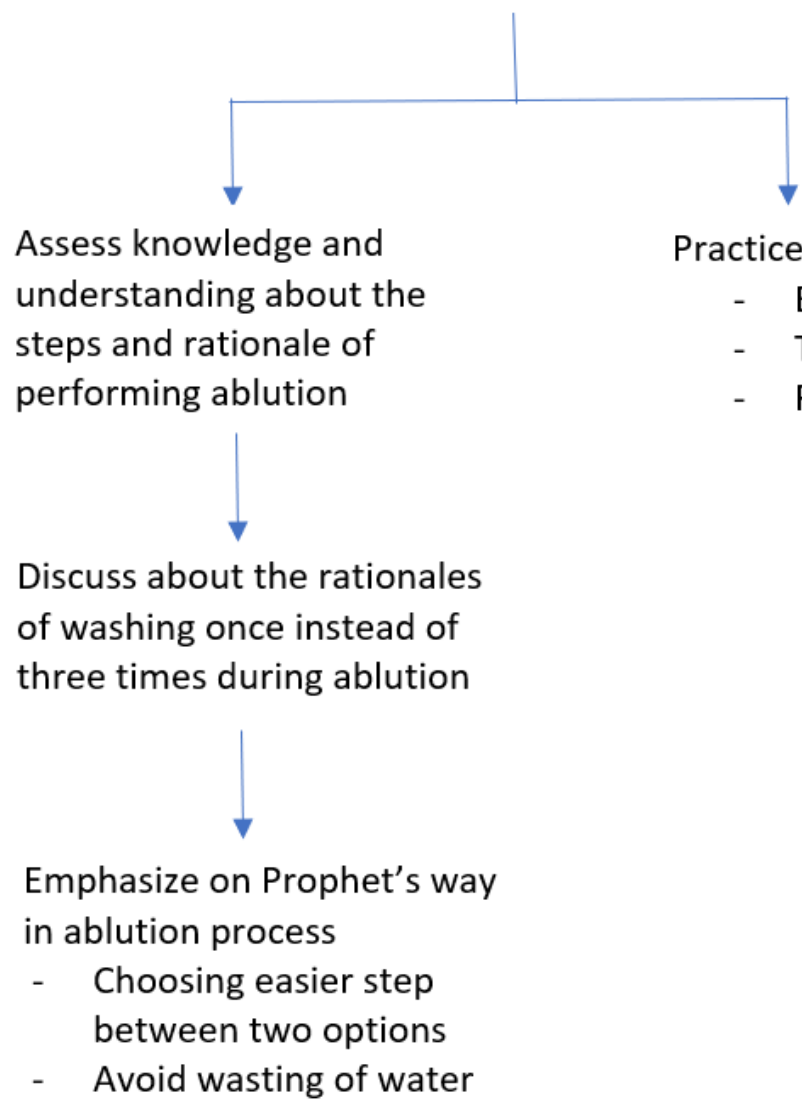
Practice behavioural therapy
- Breathing exercise
- Thought-stopping
- Response prevention

Figure 1. Algorithm for the treatment of ablution ritual related OCD 
OCD.

Children at this age (12 years of age and above) are at the formal operational stage of Piaget cognitive development [6] where they begin to think abstractly. They conceptualise and create logical structures that explain their physical experiences. They need a clear explanation of similar or additional information to complement what their Ustaz has demonstrated in their Islamic Education classes. If we fail to explain to what they expected, they might continue to search other sources such as the internet and other unreliable sources which may worsen the intrusive thought of incomplete wudhu, hence making them feel that their salat is invalid. These vicious cycles of obsessional thought must be prevented.

As compared to adult, the management of OCD in children is relatively easier because children with OCD experienced lesser intrusive thoughts and less distressed [7]. If we can identify the early signs and symptoms of OCD, early intervention can be initiated that suits the children's cognitive abilities hence preventing the worsening condition. Family involvement of young children with OCD in the therapy is vital to ensure children practice what is taught in Cognitive Behavioral Therapy (CBT) as well as compliance in the pharmacotherapy [3].

\section{Conclusion}

Children should be monitored when performing ablution because overemphasizing the practice to wash each body parts three times can become initial symptoms of OCD. Parents and teachers should have excellent knowledge and understanding about compulsory ablution and sunnah practices to help children understand the differences between these two, and appropriate to the children cognitive developmental stages.

\section{References}

[1]. Ruscio AM, Stein DJ, Chiu WT, Kessler RC. The epidemiology of obsessive-compulsive disorder in the National Comorbidity Survey Replication. Mol Psychiatry. 2010;15(1):53-63.

[2]. Geller DA, March J. Practice parameter for the assessment and treatment of children and adolescents with obsessive-compulsive disorder. Journal of the American Academy of Child \& Adolescent Psychiatry. 2012 Jan;51(1):98-113.
[3]. Rosa-Alcázar Á, Rosa-Alcázar Al, OlivaresOlivares PJ, Parada-Navas JL, Rosa-Alcázar E, Sánchez-Meca J. Family involvement and treatment for young children with ObsessiveCompulsive Disorder: Randomized control study. International Journal of Clinical Health and Psychology. 2019 Sept;19(3):218-27.

[4]. American Psychiatric Association: Diagnostic and statistical manual of mental disorders, Fifth Edition. Arlington, VA: American Psychiatric Association, 2013.

[5]. Besiroglu L, Karaca S, Keskin I. Scrupulosity and obsessive-compulsive disorder: The cognitive perspective in Islamic sources. Journal of Religion and Health. 2014 March 7;53(1):3-12.

[6]. Piaget J. Part I: Cognitive development in children: Piaget development and learning. Journal of Research and Science Teaching. 1964 Sept;2(3):176-86.

[7]. Farrell L, Barrett P. Obsessive-compulsive disorder across developmental trajectory: Cognitive processing of threat in children, adolescents, and adults. British Journal of Psychology. 2006 Feb;97(Pt 1):95-114. 